Article

\title{
Guide for Climate-Resilient Cities: An Urban Critical Infrastructures Approach
}

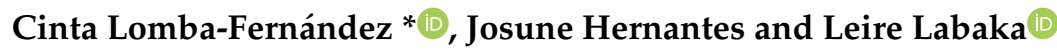 \\ TECNUN, Escuela de Ingenieros, Universidad de Navarra, 20018 San Sebastián, Spain \\ * Correspondence: clomba@tecnun.es
}

Received: 30 May 2019; Accepted: 26 August 2019; Published: 29 August 2019

\begin{abstract}
Climate change (CC) is one of the most challenging issues ever faced, as it affects every system worldwide at any scale. Urban areas are not an exception. Extreme weather-related events have seriously affected urban areas in recent years, and they have a significant impact on the welfare of people. According to UN projections, by 2050 more than $68 \%$ of the world's population could be concentrated in urban areas. Additionally, daily life in urban areas is highly dependent on certain critical services and products provided by critical infrastructures (CIs). Therefore, it is especially relevant to understand how CC affects urban CIs in order to develop mechanisms to improve their capacity to handle crises derived from CC. In this context, resilience-based strategies provide a holistic approach, considering both predictable and unpredictable threats. This paper proposes a guide for assessing and enhancing the resilience level of cities against CC, considering urban CIs as key agents in improving the city's capacity to face and recover from CC-related crises. The guide was developed through a co-creation process in which two cities in the Basque Country (Spain) worked together with CI providers and other relevant stakeholders in the resilience-building process. The resulting guide is to be used by city stakeholders at a strategic level, providing them with: (1) a qualitative assessment of the city's current resilience level in the CC context; (2) better knowledge about urban CI sectors, their interdependency relationships and the chain of impacts due to cascading effects in the short, medium and in the long term and; (3) a set of policies that enhance city resilience.
\end{abstract}

Keywords: urban resilience; critical infrastructures; interdependency analysis; climate change; assessment methodology; guide; co-creation process

\section{Introduction}

The latest scientific evidence attests to the fact that climate change (CC) is a reality and one of the biggest challenges that societies will ever have to face. Projected climate scenarios for the next 30 years pointed out in the last IPCC report highlight the seriousness of the foreseen impacts and demand urgent action be taken to slow down the effects of CC and, at the same time, face its impacts [1]. Some of the impacts that are already visible are the rising sea levels, the diminishing of Artic sea ice or more extreme weather events (in terms of an increase in the frequency and intensity of the extreme events and in the likelihood of extremely hot days and nights) [2].

In this sense, CC entails a massive challenge on a global scale that must be treated in a crosscutting manner. CC hazard affects all social, urban and ecological systems at any scale, being critical for urban environments. According to the most recent World Urbanization Prospects report put out by the United Nations (2018) [3], more than $68 \%$ of the world's population will be living in urban areas by 2050. In this way, in European cities CC is considered to be the biggest threat to sustainability, conditioning the improvement of citizens' quality of life and economic competitiveness [4]. Therefore, taking actions against $\mathrm{CC}$ will be a priority in city agendas for the next 10 years. 
The fight against the consequences of $\mathrm{CC}$ has been gaining relevance in the last three decades, and countries all over the world are taking action against CC impacts [5-8]. On the one hand, they adopt mitigation strategies with the aim of reducing greenhouse gases emissions, and on the other hand, they develop adaptation strategies in order to adjust to the current and projected future effects of CC. The standard approach to planning for climate adaptation relies on using predictions based on CC projections as the basis to identify measures for prevention. Moreover, by focusing on specific impacts, CC adaptation approaches may not consider other indirect effects or long-term stresses [9]. Nevertheless, recent studies demonstrate there is uncertainty associated with CC projections [1], as climate conditions are becoming increasingly variable and dynamic. This high degree of uncertainty requires new strategies that consider the dynamics of the threats. In this sense, traditional risk management-based approaches are not enough to deal with CC impacts.

Moreover, this context is challenging since urban areas have become more and more complex consisting of an extensive network of people, infrastructures and services that are strongly interconnected. In particular, the welfare of these urban areas is highly dependent on the proper functioning of critical infrastructures (CIs). In general, CIs are those systems and companies that provide essential services that underpin, maintain and sustain vital societal functions on which societies' wellbeing relies, for example: energy, health, food, water or order and safety $[10,11]$. CIs have adopted the technological advances to ensure a high level of reliability and safety, and by doing so, they have also grown in size and complexity. However, this growth has also increased their vulnerability and their degree of interdependency [12].

CC affects CIs in the form of acute shocks and long-term stressors causing both direct and indirect impacts due to the interdependencies [13,14]. In this sense, the failure of CIs in urban areas can have dramatic consequences for citizens. For example, hurricanes Katrina, Sandy and Harvey seriously affected the cities of New Orleans, New York and Houston in 2005, 2012 and 2017, respectively. Those events led to large crises and caused enormous damage to urban CIs and therefore to society [15] by affecting, for example, the energy and communications supply or the transportation infrastructure and services, such as the underground [16]. As CIs provide essential services in city functioning and the wellbeing of the citizens, they should be taken into account in cities' CC strategies.

In this context, cities are increasingly using resilience strategies in dealing with CC because they take a holistic approach and consider both expected and unexpected events. This holistic approach also complements other mitigation and adaptation strategies [17]. However, resilience is a broad and complex concept that is often difficult to operationalise [18]. In an urban context, that complexity is even greater due to the diversity of stakeholders and areas involved in the process of building resilience.

This paper proposes a guide to help cities to bring resilience into action by considering urban CIs as key agents in facing CC-related crises and maintaining citizens' welfare. The guide was developed through a co-creation process and with the active involvement of two cities in the Basque Country (Spain). A multidisciplinary group consisting of experts from the two cities and in areas such as energy, communications, health, water, social issues and crisis management worked together. Having all the agents participate from the early stages of the process increased their trust and their commitment to the results, which will ensure a more effective development of the city resilience strategies.

\section{State of the Art}

The concept of resilience has been widely discussed in the literature in many fields, from ecology to engineering $[19,20]$. There are two main perspectives on resilience. One of them is based on the equilibrium paradigm, that is, the capacity of a system to restore its previous state of equilibrium after a disaster, recognising the possibility of different equilibrium conditions achievable after potential disruptions [21]. The second perspective adopts a more evolutionary, dynamic and inclusive perspective, in which resilience is defined as the system capacity to adapt and adjust to changes, both internal and external [22-24]. The system's capacity to adapt to uncertainty is the key element in this second perspective. 
Regarding CIs, several approaches and proposals for building CI resilience can be found in the literature [25]. Many of them focus on technical attributes such as the robustness of the physical assets or their redundancy level [26,27], or they adopt a risk management approach and consider the system's behaviour in terms of a specific risk [28-30]. Others instead emphasise the organisational perspective, focusing on the sociotechnical attributes of CIs rather than on technical aspects [31,32]. Other frameworks recognise the importance of both technical and organisational aspects, taking into account the internal and the external limits of the CIs [33]. Regarding CC hazard, CI frameworks must consider different timescales, short, medium and long term, and the ability to deal with crises to ensure the continuity of service and be able to improve and innovate [34].

Urban CIs form complex and strongly interconnected networks that are affected by CC impacts [35-37]. In this sense, interdependency relationship analysis among CIs is a cornerstone for a reliable, safe and secure CIs system operation that ensures the critical services, even in the case of major disruption, as interdependencies are the cause of many indirect impacts and cascading effects $[38,39]$. Furthermore, interdependencies among CIs can be determinant for the recovery phase of a crisis and must be taken into account $[40,41]$.

In 2014, the IPCC defined resilience in the field of CC as "the capacity of social, economic and environmental systems to cope with a hazardous event or trend or disturbance, responding or reorganising in ways that maintain the essential function, identity and structure while also maintaining the capacity for adaptation, learning and transformation" [42]. This definition is influencing how cities are adopting their resilience strategies against CC. In this context, resilience is strongly linked to disaster risk reduction, vulnerability reduction and sustainable development $[43,44]$. In fact, sustainability and resilience approaches are often compared in the CC domain as they share the adoption of a dynamic systems approach, which considers the intrinsic complexity due to the interconnectedness among the different parts of the system and takes into account the long-term influence in a holistic manner $[45,46]$.

With regard to cities, urban systems are adopting resilience strategies to deal with both acute shocks and chronic stresses. Resilience-based strategies are being applied to face global hazards as $\mathrm{CC}$ in the crisis management field or in urban planning [43], being a central driver providing a more comprehensive, multidisciplinary perspective and establishing collaborations among different agents to improve social welfare in cities [47]. The literature offers different definitions of and approaches to city and urban resilience. Some of them focus on a city's capacity to face crises, in terms of appropriate resources and capacities to minimise the negative effects of the crises [48,49]. Others highlight the relevance of institutional strength, like having a central government, private companies and non-governmental institutions that have the ability to anticipate and respond to events [50]. Meerow (2016) proposes a definition of urban resilience based on the dynamic behaviour of the urban system in facing disturbance and its adaptive capacity to manage in a changing environment [51].

Initiatives such as 100 Resilient Cities are also helping cities to become better prepared against disasters by providing them with technical support and resources to help them to develop and set up resilience strategies [52]. Such initiatives propose a resilience framework based on four fundamental dimensions: (1) health and wellbeing, (2) leadership and strategy, (3) infrastructure and environment and (4) economy and society.

Other tools and methodologies are being developed to help cities and their infrastructures to face current global challenges, including CC, from a resilience approach [53-55] and from risk assessment approaches, focusing on vulnerability analyses in light of previously identified CC-related risks [56].

All these frameworks and methods recognise the importance of critical infrastructures on city resilience. In this sense, the city resilience level depends, to a large extent, on the resilience level of its CI, which in turn depends on the resilience level of other CIs, given their interdependences [57]. Although many studies have analysed urban CI interdependency, they often focus on a specific CI and the effect an extreme weather-related event has on it [58], lacking a more holistic analysis which takes into account the whole urban CI network in the context of CC. 
This paper proposes a guide to help cities to bring resilience into action by considering urban CIs as key agents to cope with CC-related crises and maintain citizens' welfare.

\section{Methodology}

The objective of this research was to develop a guide to help cities to improve their resilience level against CC taking into account their urban CIs. Figure 1 shows the overall research methodology used in the research, which consisted of two phases: the conceptualization phase and development phase. The outcomes obtained in each phase contributed to the development of the resulting resilience guide.

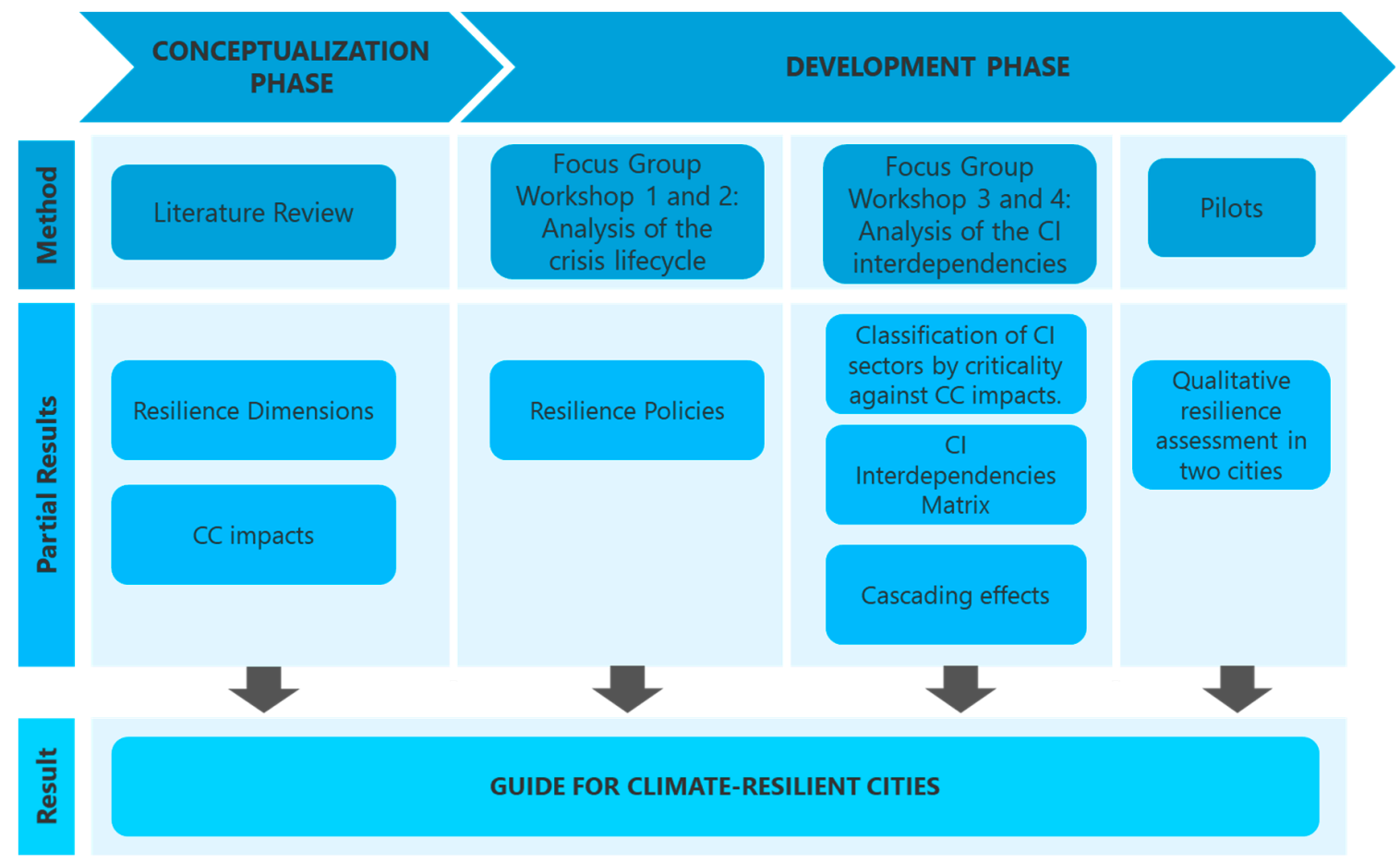

Figure 1. Methodology of the research.

In the conceptualisation phase, a literature review was carried out with the aim of establishing the theoretical bases for the future guide. Two objectives were set for this first phase of the research: (1) identify the resilience dimensions and (2) understand how CC affects CIs. In this sense, scientific and grey literature articles and reports were analysed to get as wide a view as possible about the resilience frameworks related to CC and CIs.

In the development phase (see Figure 1), as the active participation of all the relevant stakeholders is essential to elaborate a strategy for increasing the resilience of urban $\mathrm{CI}$, a co-creation approach was adopted [59]. This ensures that all the information, perspectives and needs are being considered in the resulting guide, increasing the success of the resilience strategy [18]. In this sense, co-creation processes are effective methods for integrating experts' fragmented knowledge and delivering insights into the resilience-building process. In addition, co-creation processes ensure that the strategies are created specifically for the needs of the end users [60]. Focus group discussions are effective for exploratory studies and for observing diverse experiences and perspectives and building consensus among experts on a topic of study [61].

In this research, the focus group method was used to elicit information about improving the resilience of urban CIs in the face of CC from experts in two cities (two workshops in each city). As a result of the first two focus group sessions (W1 and W2) the resilience building policies for improving urban CIs resilience level were identified. In the next two workshops (W3 and W4), a more focused 
analysis regarding CIs was carried out, getting as a result the classification of the CIs against CC impacts and the interrelationships among CIs and their cascading effects.

Finally, two pilot tests (one in each city) were carried out to review the guide and use it in a real context. Below, a more detailed explanation about the execution of these focus group sessions and pilot tests is given.

This research was carried out within the context of the Basque Climate Change Strategy-Klima 2050. In this sense, two urban areas in the Basque Country actively contributed to the development of the guide: one is the capital of a Basque province and the other is a smaller town. These two cases were selected to characterise most of the Basque councils' reality in terms of the following criteria: size, number of citizens, level of commitment in confronting CC, and CC impacts.

Thirty multidisciplinary experts from both cities participated in this co-creation process by providing the strategic, operational and tactical background. In this sense, participation was broad with the involvement of the potential end users, namely the city councils, and other actors from the CI sectors. Table 1 shows the affiliation and area of expertise of the 30 experts who actively participated in the overall co-creation process, that is, in the focus groups and the pilots.

Table 1. Panel of experts by affiliation and area of knowledge.

\begin{tabular}{cc}
\hline AFFILIATION & AREA OF KNOWLEDGE (Number of Experts) \\
\hline City Council (Cities 1 and 2) & Environment and climate change adaptation (4) \\
\hline City Council (Cities 1 and 2) & Urban infrastructure maintenance (3) \\
\hline City Council (City 1) & Strategy development (2) \\
\hline City Council (City 2) & Social issues (1) \\
\hline Osakidetza (Basque Country's public health service) & Health (4) \\
\hline $\begin{array}{c}\text { Basque water agency. } \\
\text { Provincial water agency. } \\
\text { Aguas del Añarbe. }\end{array}$ & Energy (electricity) (3) \\
\hline $\begin{array}{c}\text { REE. } \\
\text { Iberdrola }\end{array}$ & ICT (1) \\
\hline $\begin{array}{c}\text { DonostiTIK } \\
\text { Municipal police (City 2). }\end{array}$ & Safety and order (3) \\
\hline $\begin{array}{c}\text { Ertzaintza (Basque Country's police force) } \\
\text { Red Cross. }\end{array}$ & First responders (1) \\
\hline Provincial council's firefighters & First responders (volunteers) (5) \\
\hline \begin{tabular}{c} 
Civil Protection. \\
\hline
\end{tabular}
\end{tabular}

In the focus group sessions, the conceptual framework showed in Figure 2 was used for the analysis of the effect of CC on urban CI systems and, as a result, on the society.

The focus groups worked over a series of four workshops, two in each city. In the workshops, they worked with CC-related crisis scenarios based on the CC impacts identified in the previous phase of the research (conceptualization phase).

First, the capacity of the cities to cope with those CC-related crises was analysed. To that aim, two workshops (W1 and W2) were organized, one in each city. The objective of these workshops was to identify the policies that are most relevant in enhancing urban CI resilience against CC by considering the capacity of the city to cope with big crises. 


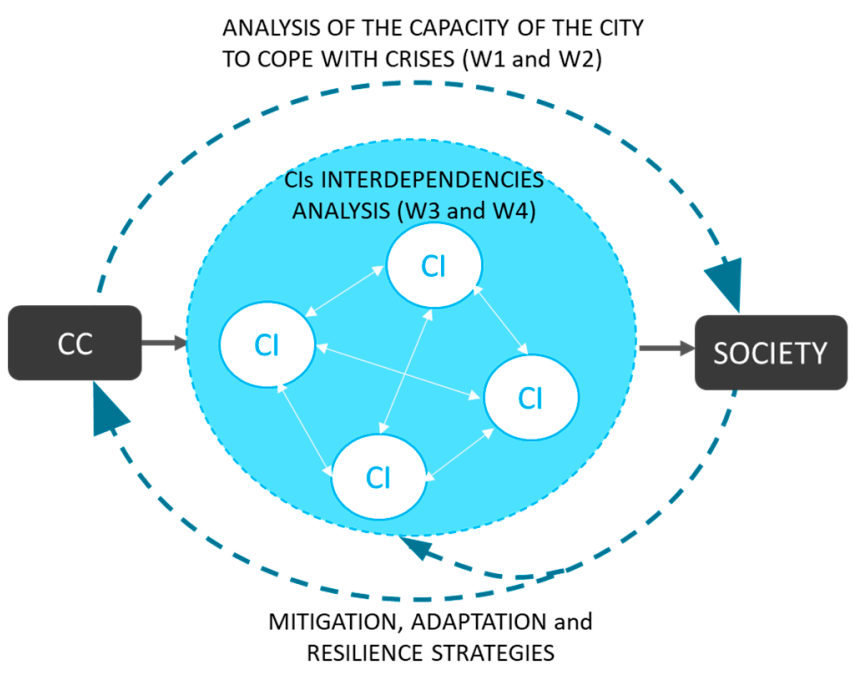

Figure 2. Conceptual framework for the analysis of the effect of climate change (CC) on cities.

Once the resilience-building policies were identified, the analysis focused on the effect of CC on the urban CI system, the interdependency relationships among the CIs, and the consequences of such interdependencies in the society. With that aim, two more workshops were organised (W3 and W4). The focus group had the objective of analysing how CIs that are affected in CC-related crises affect other CIs due to their interdependencies and how this in turn affects society.

In the workshops, the participants identified current experiences and best practices related to crises resolution and to the management of $\mathrm{CI}$ interdependency. Moreover, they reflected on the difficulties and main barriers to the operationalisation of the resilience strategies.

The outcomes of the four workshops were:

- $\quad$ W1, W2, W3 and W4: a list of policies for improving city resilience against CC.

- W3 and W4: a classification of CI sectors by criticality against CC impacts, a CI interdependency matrix and the chain of socio-economic impacts to the society due to cascading effects.

Additionally, the process itself reported benefits, such as the creation of a collaborative environment for constructive partnership, learning and trust among the participants.

Once a preliminary version of the guide was created, based on the insights obtained during the focus group sessions and the literature review, it was pilot-tested with the two cities participating in the project, since they are to be the final users of the methodology. These cities had the opportunity to review the guide and use it to carry out a self-assessment of their resilience level. This allowed them to obtain a qualitative assessment of their capacities to deal with CC-related crises based on the tools proposed in the guide. This assessment provided the cities with a diagnosis of how resilient they were and what could be done to improve their resilience.

After the self-assessment, several interviews with the cities' personnel were carried out with the objective of analysing important aspects of the guide with regard to its degree of eligibility, its usefulness and its user-friendliness. In this sense, technicians of the environmental department of the two cities involved in the development phase were interviewed to get information about the process itself and about the resulting guide. Moreover, additional interviews with the heads of the environmental departments of eight towns which had not participated in the development phase were carried out. The information gathered was used to improve the guide.

\section{Results}

The main result of this research was a guide to help cities with reflection on the key aspects that will lead them to develop actions for enhancing their resilience against CC events by focusing on urban CIs. 
The guide consists of a three-step process. The first step aims at contextualising the characteristics of the urban area under analysis and the CC related risks to which the urban area is exposed. The second step is focused on the analysis of urban CI networks, deepening the understanding of the interrelationships between CIs and the socio-economic consequences in society in cases of CI disruption. Finally, the last step aims to make a diagnosis of the current resilience level and how to improve it. The guide proposes the profiles of the stakeholders that should take part in the process to achieve a successful outcome. For each step a set of questions to be answered are proposed. Those questions address key issues that the city should take into account to develop its resilience strategy. To facilitate the process, the guide proposes several activities and tools, which have been designed to work in detail the aspects of the crisis management system or the $\mathrm{CI}$ interdependency relationships in the city.

By using the guide, the cities will obtain the following outcomes: (1) a set of policies for enhancing city resilience; (2) greater knowledge about urban CI sectors, their interdependency relationships and the chain of impacts resulting from cascading effects in the short and long term; and (3) a qualitative assessment of the city's resilience level in the CC context.

The three steps proposed by the guide are:

1. Understand the urban context and CC-related crises.

2. Understand urban CI networks, sectors and services.

3. Assess and improve resilience.

Figure 3 describes the guide with the three steps, the activities, the outcomes and the stakeholders recommended for each step.

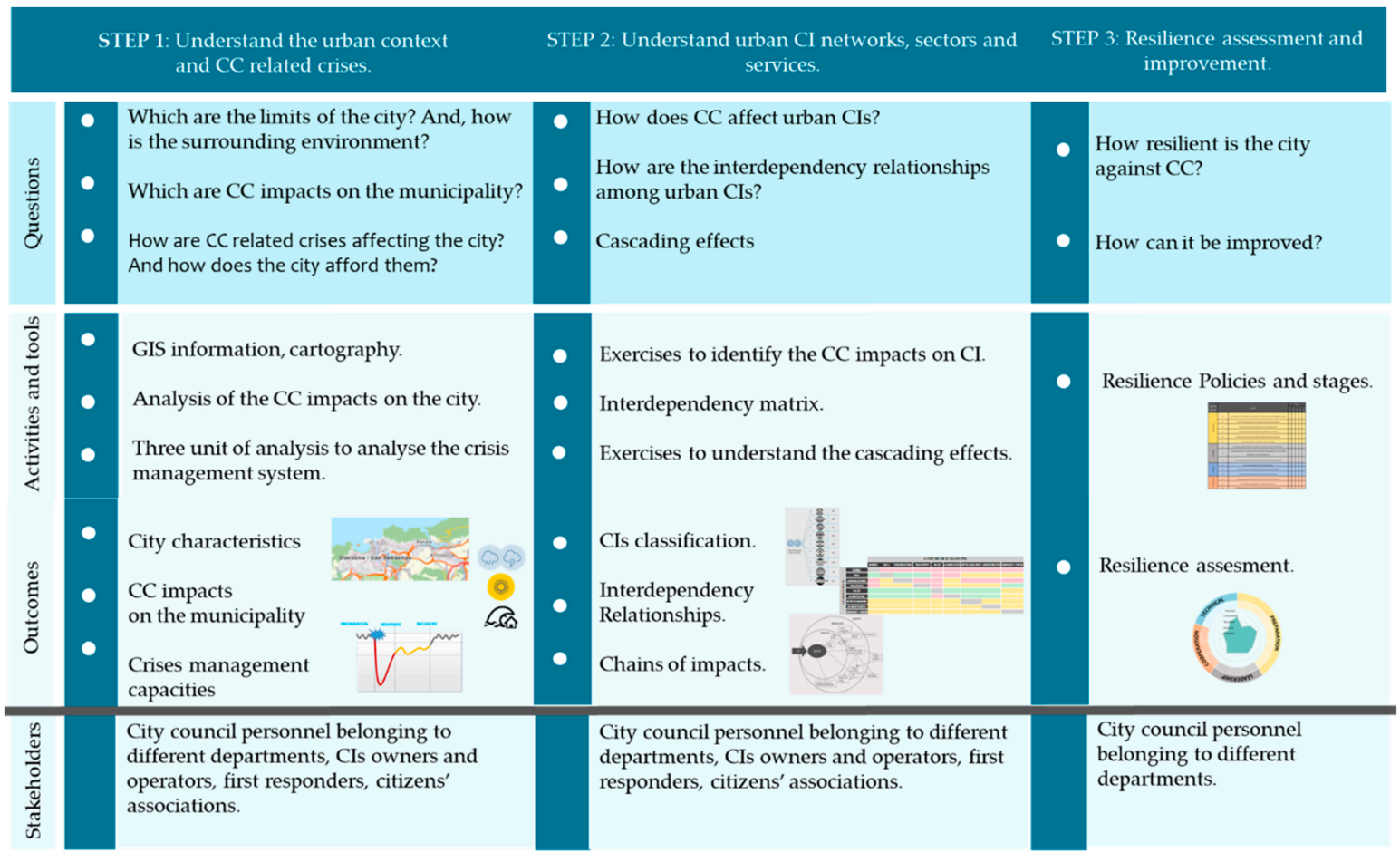

Figure 3. Guide for climate-resilient cities.

The three steps are described in detail in the following three subsections.

\subsection{Step 1: Understand the Urban Context and CC-Related Crises}

The first step of the guide consists of defining the limits of the analysis. To that end, the urban environment must be defined in terms of its physical limits and main characteristics, as described 
below. In addition, critical services and critical assets must be identified. In this sense, CIs inside the city boundaries must be considered, but so must those that are outside the city's limits but provide critical services for the city. This is the case for smaller cities where certain services, like health or emergency services, are usually provided at the regional level.

In this first step, cities must go through the following set of questions:

(1) Which are the limits of the city? And what is the surrounding environment like?

It is necessary to clearly establish the area of analysis, and the first step is to set the physical limits of the city. For this purpose, the use of tools based on Geographical Information Systems (GIS) technology, like cartographic maps, can be useful. Moreover, the surrounding environment must be detailed. In this sense, the most relevant geographical characteristics of the city and its area of influence must be described: altitude, coastal and/or river environment, slopes, etc., as those characteristics are strongly linked to specific climate chains of impacts.

Then, the CIs that provide critical services for the city must be identified; these include the ones that provide energy, water, communications, health, transportation, etc. In this sense, all the assets and providers inside the city boundaries should be considered along with those that are outside the city but provide it with critical services. This could be the case, for example, of dams, electrical substations, fuel tanks, or in some cases and especially in smaller cities, hospitals or fire stations.

(2) What are the CC impacts on the city?

To adopt effective action against CC impacts it is necessary to understand how CC affects the city or the region under study. For that reason, an exhaustive risk analysis focused on CC-related risks must be conducted. Cities must be prepared for both the events with a high probability of occurrence and the unpredictable events, as CC impacts are associated with a high degree of uncertainty. To that end, cities can gather information by analysing reports and developing projects that help them to clarify the effects of CC impacts on their surrounding environment.

(3) How are CC-related crises affecting the city? And how does the city face them?

The objective of this part of the analysis is to understand the capacity of each city to face CC-related crises, both expected and unexpected, by setting the most significant activities for each of the phases of a crisis: prevention, response and recovery. For this purpose, focus group sessions should be carried out, involving multidisciplinary groups of experts to reflect on CC impacts, with the objective of improving their preparation and identifying the key capacities that will lead them to a successful crisis resolution. For this purpose, the guide proposes using triggering events such as extreme weather-related events that represent acute shocks as potential crisis scenarios in addition to analysing scenarios based on long-term stressors. This would be the case, for example, for the increase in the frequency and severity of heat waves due to the rise in the average global temperatures.

As a result, the city will identify the set of actions that should be performed in the case of eventual crises, in addition to information such as who the most relevant stakeholders in crisis resolution are.

To illustrate, Table 2 shows some of the prevention activities identified by the experts during the focus group sessions, as well as some barriers to their implementation.

The focus group sessions carried out in both cities allowed the cities to become aware of what they are already doing, and it also alerted them to what they need to improve in order to be better prepared when crisis strikes. 
Table 2. Prevention activities and barriers to their implementation.

\begin{tabular}{|c|c|}
\hline ACTIVITIES & BARRIERS \\
\hline Carry out training and drills. & \multirow{6}{*}{$\begin{array}{l}\text { Lack of political consensus on CC issues. } \\
\text { Politicians do not take expert and CI opinion into } \\
\text { account when legislating. } \\
\text { Lack of knowledge about more sustainable solutions. } \\
\text { Economic issues. } \\
\text { Lack of citizen awareness about CC. }\end{array}$} \\
\hline $\begin{array}{l}\text { Consider CC criteria in the design and planning of } \\
\text { new installations. }\end{array}$ & \\
\hline Carry out risk assessment and identify critical points. & \\
\hline Design and implement resilience plans. & \\
\hline Promote CC awareness. & \\
\hline $\begin{array}{l}\text { Create a panel of experts to give advice to decision } \\
\text { makers on CC issues, and keep it updated. }\end{array}$ & \\
\hline
\end{tabular}

\subsection{Step 2: Understand Urban CI Networks}

The second step of the methodology defines how to carry out the urban CI network analysis.

CIs are very complex systems and highly interdependent $[62,63]$. Due to the importance of the service they offer, it is of paramount importance to understand how CC affects CIs, their interdependency relationships, and the short and long-term consequences of failure.

A structured process for finding out the information consists of answering the following three questions:

\section{(1) How does CC affect urban CIs?}

The guide proposes one exercise to analyse the effect of CC impacts on urban CIs with the objective of identifying the most critical sectors for the city. For this purpose, experts will work with different events or crisis scenarios associated with CC impacts, and they should reflect on how this specific CC scenario can affect different $\mathrm{CI}$ sectors. These sectors can be classified according to their criticality for the city on a scale from 0 (none) to 5 (very high) and by taking into account a specific CC scenario.

To illustrate, Figure 4 shows the results of the study carried out in one of the analysed cities. On the left is the effect that a severe chain of squalls has on urban CIs and on the right is the effect that a heat wave has on urban CIs. The numbers represent the average of all the experts' answers.
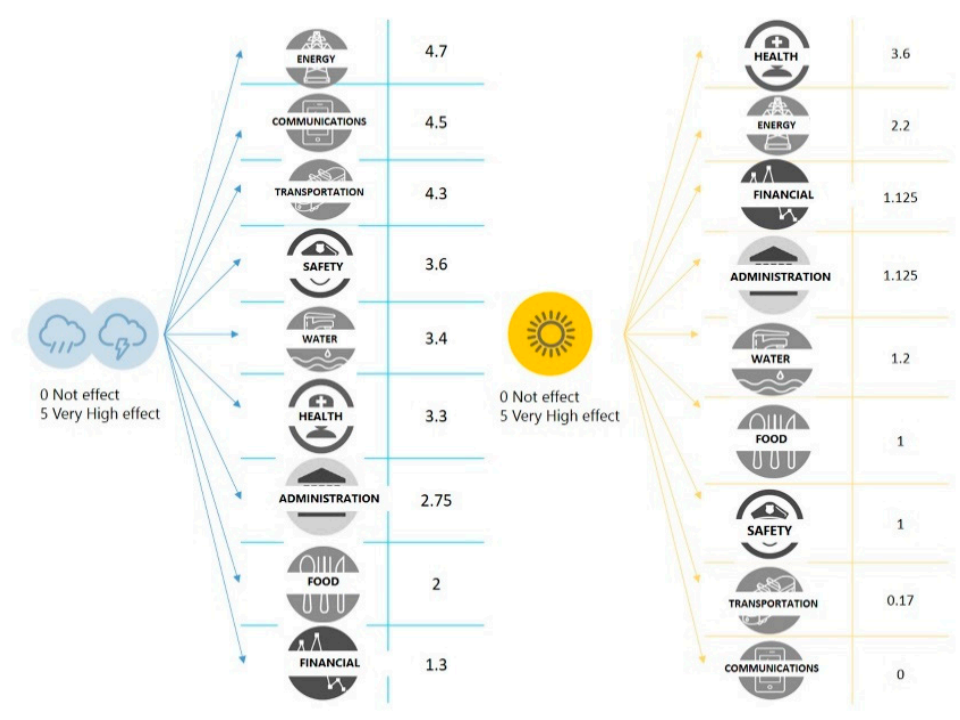

Figure 4. Classification of urban CI sectors, by criticality, in two different crisis scenarios.

In the case of the extreme weather event, the experts in the workshops agreed that the most vulnerable sectors are those whose facilities are likely to be affected by such extreme events. The energy sector was rated especially vulnerable with a score close to 5 , due to the exposure of its facilities. In the 
heat wave scenario, the energy sector was not perceived to be particularly vulnerable, as it was given a value of 1 . This scenario rates very highly, however, for the health sector, as heat waves have a significant impact on vulnerable populations such as the sick, elderly and young children.

This analysis highlights the most critical sectors in terms of CC impacts in the city, and therefore, the ones that must be considered first in order to minimise the effect of an eventual failure.

(2) What are the interdependency relationships among urban CIs like?

CIs are tightly coupled systems constituting very complex and strongly interconnected networks. The interdependencies among CIs mean that the failure of one CI can spread to others due to indirect impacts and cascading effects, aggravating the crisis and ultimately affecting society. Furthermore, they can be determinant for the recovery phase of one crisis. In this sense, it is necessary to identify the consequences that the failure of one CI has on the others.

The guide developed proposes using a matrix to analyse the level of interdependencies [38]. The proposed matrix establishes the effect of one CI failure on other CIs, by defining three degrees of dependency: low, medium and high. Moreover, it is useful to establish a temporal range of autonomy before the dependency becomes critical. This information is relevant for decision makers in order to establish appropriate auxiliary measures to limit or completely remove the negative effects of those dependencies.

Figure 5 shows the sectorial interdependencies matrix resulting from the analysis carried out in one of the cities under study. All the dependency relationships marked as high in the matrix must be analysed in depth.

\begin{tabular}{|c|c|c|c|c|c|c|c|c|c|c|}
\hline & \multicolumn{9}{|c|}{ CI AFFECTED BY OTHER FALILD CI } \\
\hline & & ENERGY & WATER & COMMUNICATONS & TRANSPORTATION & HEALTH & FOOD & FINANCIAL & ADMINISTRATION & $\begin{array}{c}\text { SAFENY } \\
\text { AND } \\
\text { ORDER }\end{array}$ \\
\hline \multirow{9}{*}{$\mathbb{E}$} & ENERGY & & HIGH & $\mathrm{HIGH}$ & HIGH & $\mathrm{HIGH}$ & HIGH & HIGH & HIGH & HIGH \\
\hline & WAIER & Low & & LOW & LOW & HIGH & HIGH & MEDIUM & MEDIUM & MEDIUM \\
\hline & COMMUNICATONS & HIGH & MEDIUM & & HIGH & HIGH & MEDIUM & $\mathrm{HIGH}$ & HIGH & HIGH \\
\hline & TRANSPORTATION & $\mathrm{HIGH}$ & MEDIUM & MEDIUM & & HIGH & MEDIUM & MEDIUM & MEDIUM & LOW \\
\hline & HEALTH & Low & Low & LOW & Low & & Low & LOW & LOW & MEDIUM \\
\hline & FOOD & Low & Low & LOW & LOW & LOW & & Low & Low & MEDIUM \\
\hline & FINANCIAL & MEDIUM & MEDIUM & MEDIUM & MEDIUM & MEDIUM & MEDIUM & & MEDIUM & MEDIUM \\
\hline & ADMINISIRATON & MEDIUM & MEDIUM & MEDIUM & MEDIUM & MEDIUM & MEDIUM & MEDIUM & & MEDIUM \\
\hline & SAFETY AND ORDER & MEDIUM & MEDIUM & MEDIUM & MEDIUM & MEDIUM & MEDIUM & MEDIUM & MEDIUM & \\
\hline
\end{tabular}

Figure 5. Interdependency matrix resulting from the sectorial analysis carried out in one city.

(3) When CIs fail, what are the consequences that result from cascading effects in the short and in the long term?

When analysing cascading effects due to $\mathrm{CI}$ interdependency, usually the analysis focuses on the short-term consequences. However, it is necessary to understand how the short-term effects spread to other sectors in the long-term in CC-related crises.

The guide proposes an exercise to analyse the chains of impacts in the short and in the long term. The analysis should focus on the most critical sectors that have been already identified. In this case, the experts will work once again with different events or crisis scenarios associated with CC impacts but on a specific $\mathrm{CI}$ sector, for example the energy sector. They must reflect on the direct and indirect effects due to the failure of the $\mathrm{CI}$ under study on another $\mathrm{CI}$ sectors and on society, taking into account both the short- and the long-term consequences.

This information will lead to more effective crisis management, as preparation and restoration actions can be identified. Moreover, the acquired knowledge will be useful for identifying the mitigation and adaptation measures that can be considered in future CI design and planning, introducing a CC perspective. In this sense, the experts who participated in the sessions proposed ideas like using materials that perform better in adverse climate conditions in the design of new structures and in the renovation of existing ones. Other proposals were related to the need for governance and legal frameworks that promote the development and adoption of mitigation and adaptation actions. 
Figure 6 shows the result of the analysis carried out in one the cities, in which the chain of impacts on the energy sector due to CC was analysed.

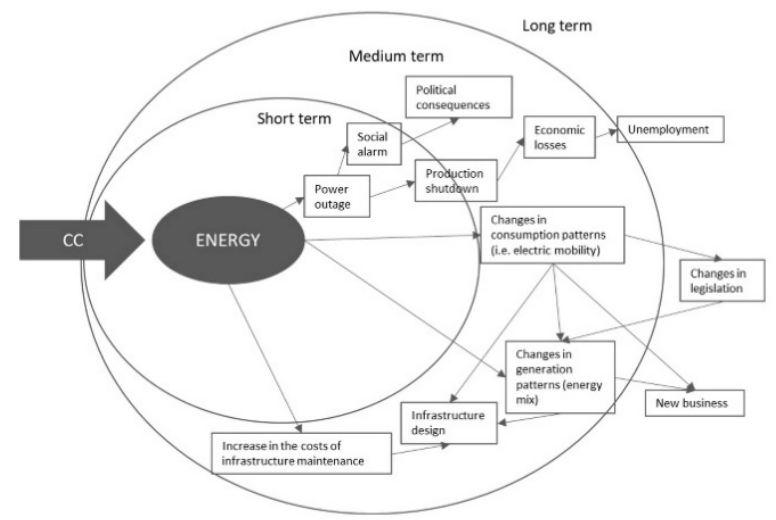

Figure 6. Chain of impacts on the energy sector classified into short-, medium- and long-term impacts.

In general, the focus group sessions highlighted that cities are more aware of extreme events, like hurricanes, than they are of long-term stressors, like the sea level rise or the increase of the global temperature average. Moreover, they find it difficult to foresee CC consequences in the long term. In any case, to develop effective measures against CC impacts the long term must be taken into account.

\subsection{Step 3: Assess and Improve Resilience}

The third step of the guide aims to answer two relevant questions: (1) How resilient is the city against CC? Moreover, (2) how can it be improved?

To answer these two questions, the guide proposes a framework for assessing city resilience against CC considering CIs to be key agents in the resilience-building process. The framework consists of 15 policies that were identified in the focus group sessions (W1, W2, W3 and W4), explained in methodology section, and then contrasted and complemented with others from existing resilience frameworks analysed in the literature review. The policies were classified in the following resilience dimensions: preparedness, leadership, technical and cooperation, based on existing city resilience frameworks [18,64-66] and existing CI resilience frameworks [28,29,33].

A brief description of the dimensions is provided below.

- PREPAREDNESS. This dimension refers to the capacity of the city to anticipate and adapt its services and functions to future needs. It comprises city and urban CI skills for managing the unexpected in terms of knowledge, procedures and technical resources for improving their flexibility and adaptive capacity.

- LEADERSHIP. This dimension refers to city commitment to the resilience-building process and its capacity to promote and consolidate the culture, attitude and values based on it. Furthermore, it considers the capacity of the city to develop strategies involving all relevant stakeholders in the city. City leaders must ensure an accurate and stable legal and operational environment that enables and guarantees the adoption and improvement of the resilience policies.

- TECHNICAL. This dimension refers to the city infrastructures' strength and capacity for adapting to the CC hazard and its impacts, in terms of resisting, absorbing and recovering from a triggering event, while guaranteeing the service. In this sense, CIs must carry out effective risk management and establish redundancy measures and resources to reduce vulnerabilities as well as to face and solve crises, both expected and unexpected. This includes having physical assets, staff, skills, technology, supplies and ensuring reliable and good quality information.

- COOPERATION. This dimension refers to the capacity of the city agents to work together and set and achieve common purposes. Cooperation must be developed at all levels within the city 
and at the supra-municipal level, involving agents belonging to the public, private and social spheres. In this dimension, policies to promote effective collaboration and agreements among all city agents with the objective of enhancing city resilience can be found. Moreover, actions that promote strategic alliances with other cities and lead to the creation of resilient cities networks must be carried out.

The proposed framework provides a qualitative assessment of resilience by evaluating the degree of implementation of the resilience policies. Assessment gives cities the opportunity to analyse their current situation and identify opportunities and challenges supporting the development of resilience-strengthening strategies.

Table 3 shows the resilience policies organised on the four resilience dimensions.

Table 3. Resilience policies.

\begin{tabular}{|c|c|c|c|c|c|c|c|}
\hline \multirow{2}{*}{$\begin{array}{l}\text { RESILIENCE } \\
\text { DIMENSION }\end{array}$} & \multirow{2}{*}{\multicolumn{2}{|c|}{ POLICIES }} & \multicolumn{5}{|c|}{ STAGE } \\
\hline & & & $\mathbf{E}$ & $\mathbf{M}$ & $\mathbf{A}$ & $\mathrm{C}$ & $\mathbf{P}$ \\
\hline \multirow{6}{*}{ PREPARATION } & P1 & $\begin{array}{l}\text { To evaluate risks and to identify critical } \\
\text { elements, both physical assets and management } \\
\text { processes. }\end{array}$ & & & & & \\
\hline & P2 & $\begin{array}{l}\text { To ensure the preparation of crisis managers } \\
\text { and public and private agents. }\end{array}$ & & & & & \\
\hline & P3 & $\begin{array}{l}\text { To define, improve and update the crisis } \\
\text { management plans. }\end{array}$ & & & & & \\
\hline & $\mathrm{P} 4$ & $\begin{array}{l}\text { To have adequate equipment and resources to } \\
\text { face and solve crises. }\end{array}$ & & & & & \\
\hline & P5 & $\begin{array}{l}\text { To analyse previous crises and share the } \\
\text { knowledge with other cities. }\end{array}$ & & & & & \\
\hline & P6 & $\begin{array}{l}\text { To develop activities for natural environment } \\
\text { monitoring. }\end{array}$ & & & & & \\
\hline \multirow{3}{*}{ LEADERSHIP } & L1 & $\begin{array}{l}\text { To lead the resilience-building process against } \\
\text { CC being an example for the citizenry. }\end{array}$ & & & & & \\
\hline & $\mathrm{L} 2$ & $\begin{array}{l}\text { To adapt the regulations and standards to the } \\
\text { real needs and realities applying CC criteria } \\
\text { (energy, infrastructures, urban } \\
\text { development, etc.). }\end{array}$ & & & & & \\
\hline & L3 & $\begin{array}{l}\text { To carry out activities to generate awareness in } \\
\text { and commitment from all the city agents. }\end{array}$ & & & & & \\
\hline \multirow{3}{*}{ TECHNICAL } & $\mathrm{T} 1$ & $\begin{array}{l}\text { To ensure the reliability of the urban } \\
\text { infrastructures. }\end{array}$ & & & & & \\
\hline & $\mathrm{T} 2$ & $\begin{array}{l}\text { To renew and improve existing infrastructures } \\
\text { by introducing CC criteria. }\end{array}$ & & & & & \\
\hline & $\mathrm{T} 3$ & $\begin{array}{l}\text { To manage CIs interdependencies at the } \\
\text { sectorial and local levels. }\end{array}$ & & & & & \\
\hline \multirow{3}{*}{ COOPERATION } & $\mathrm{C} 1$ & $\begin{array}{l}\text { To encourage cooperation and solidarity among } \\
\text { citizens to better face crises. }\end{array}$ & & & & & \\
\hline & $\mathrm{C} 2$ & $\begin{array}{l}\text { To set collaboration agreements with CI } \\
\text { providers to face CC. }\end{array}$ & & & & & \\
\hline & $\mathrm{C} 3$ & $\begin{array}{l}\text { To establish appropriate communication } \\
\text { channels and people responsible for them. }\end{array}$ & & & & & \\
\hline
\end{tabular}

To help practitioners evaluate each policy, a path with five stages is proposed, the stages being: (1) emerging, (2) moderate, (3) advanced, (4) consolidated and (5) proactive. 
A brief description of each stages is provided below.

- $\quad$ EMERGING (E): The city is aware of the need, but they do not know how to operationalise it. In the emerging stage, the policies are based on basic risk assessment without considering a multi-hazard approach. Preparedness for CC impacts on the urban environment, and specifically on CIs, is still incipient. Protocols and procedures for crisis management are basic and have been developed at the sectorial level and with little to no coordination. CC is not considered in urban planning or in CI renovation and construction. The city has little knowledge about the CIs and their interdependency relationships. Coordination and cooperation among the city stakeholders are defined only for specific actions.

- MODERATE (M): Basic measures according to regulations are implemented. The objective of the actions is to reach the minimum targets (i.e., risk assessment, $\mathrm{CO}_{2}$ emissions, etc.). Policies at the moderate stage start to introduce the resilience approach. In this sense, risks are considered from a more holistic approach taking into account CC impacts. Moreover, the knowledge about critical services is improved but still lacking an overall view of the urban CIs and their interdependencies. Punctual actions to face CC are carried out at the sectorial level, although specific local regulation for CC does not exist. Cooperation among stakeholders is being formalised to face specific threats.

- ADVANCED (A): The actions carried out are coordinated with other policies and departments within the city government. In the advanced stage, the city understands the main risks, including CC-related threats, in a holistic manner but still lacks integrated plans and preparation activities, especially with regard to urban CIs. The city is developing CC adaptation plans, mainly in the environmental department, and considering a CC perspective in their urban planning. The city has improved its knowledge about CI interdependency relationships at the sectorial level. The city government, urban CIs and other relevant stakeholders establish cooperation agreements for CC-related issues.

- CONSOLIDATED (C): The actions carried out are coordinated within the city government as well as with CI providers and other relevant city stakeholders. In the consolidated stage, the city has developed coordinated plans to face risks from a multi-hazard approach in some specific situations. Those plans consider the urban CIs and other relevant stakeholders. The city is developing its resilience strategy and has CC adaptation action plans, but they are not aligned. The city has developed plans to build a CC perspective in the renovation and design of urban CIs. The city understands CIs interdependency relationships at the sectorial level, and in the most critical cases, at the local level. The city jointly develops its resilience plan with urban CIs and other relevant stakeholders.

- $\quad$ PROACTIVE (P): Policy development and improvement is promoted in a proactive manner among all the agents involved. In the proactive stage, the city has a resilience strategy that integrates other specific strategies such as CC plans. The city understands and manages the interdependencies of the CIs at the sectorial and local levels. Moreover, the interdependencies are managed beyond the city boundaries. The integration and coordination among all the relevant stakeholders, the city government, the CIs and other groups of interest are complete at the local level and coordinated with other relevant stakeholders at the regional level.

The proposed framework has been used to assess the resilience level of the cities that participated in the project (see Figure 7). In order to self-assess their resilience level, they evaluate the level of implementation of each policy taking into account the five stages proposed within this guide. 

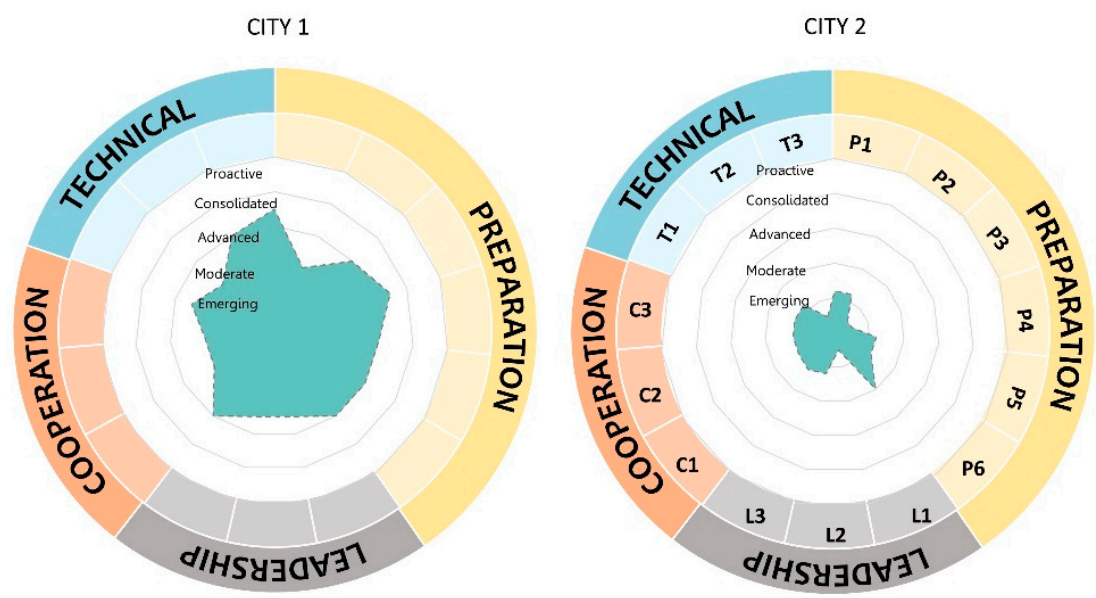

Figure 7. Resilience assessment for the two cities under study.

The assessment results allow cities to see how resilient they are against CC, in addition to identifying the areas of improvement for each dimension.

Based on the results, it can be seen that City 1 has a higher resilience level than City 2, as the degree of implementation of the resilience policies is, in general, bigger in City 1 than in the City 2. This is due to the fact that the bigger city, City 1, has more resources and more autonomy than the smaller one, City 2. In this sense, City 1 is familiar with the concept of resilience and already has a CC adaptation action plan, as can be seen in the values of the policies for the leadership and preparation dimensions. Moreover, they have carried out projects to understand their urban CIs and their interdependencies, as the technical dimension analysis shows. In contrast, for City 2 resilience is a new approach, and although they are aware against CC impacts, they are starting to design their strategy to deal with its effects, as can be seen in the analysis of the leadership and preparation dimensions. In the case of City 2, the technical dimension analysis reflects the fact that they have little knowledge about the $\mathrm{CI}$ sectors and their interdependencies, being a simply user-provider relationship. In the cooperation dimension, both cities have a big area of improvement, being bigger in the case of the smaller city. In this sense, the participants of City 2 pointed out that cooperation at different levels was paramount for them to solve crises, as they depend on external resources at the regional level. The study reflects this situation and suggests that for smaller cities the resilience strategy might need to be developed at the county or regional level to be more effective, considering a group of municipalities.

\section{Discussion}

CC represents a global challenge that must be addressed also on a local scale. In this sense, cities are adopting resilience-based strategies to better deal with CC impacts. However, policy makers and planners still have limited tools and knowledge for bringing resilience into action and effectively planning for a changing climate. This fact becomes even more challenging when the focus is on CI sectors, as they provide services of public interest but belong to or are operated by private companies.

The proposed guide is intended to be a starting point for cities to enhance their resilience level against CC. The guide poses that, for developing a resilience strategy, it is necessary to have in-depth knowledge of the city environment, including urban CIs, in addition to having better knowledge about the urban CI networks and their interdependency relationships.

The analysis carried out highlights that this complexity must be managed in a holistic manner. Moreover, it demonstrates that when talking about CIs and CC impacts, city boundaries are not as clear, given that some of the critical services can be provided from outside the city. For that reason, local resilience strategies must be aligned with others at the regional level. 
In this context, the guide provides several steps, activities and tools that can be used to analyse and develop the city resilience strategy. Moreover, it proposes the stakeholders that should participate in the process in order to be successful.

Several conclusions are extracted based on the results obtained in case studies of both cities. The two CC-related case studies highlighted that the magnitude of a crisis is perceived in terms of the resources or help needed. It is worth noting that the policies identified were different in both case studies. While bigger cities have their own resources to face crises, smaller cities depend on the collective use of resources. In this sense, one recurring idea was that cooperation and coordination, including citizen participation, is always an important issue and paramount for small towns.

The capacity to anticipate event occurrence is important. In this sense, historical data about weather-related indicators such as temperatures, precipitation data, water levels for rivers and dams and quality parameters for water and air acquires great relevance. Moreover, the experts highlighted the need to have proper indicators and reliable information to monitor and anticipate potential crises. In this sense, further research is needed.

Preparation is mandatory for dealing with CC-related crises. Activities promoting awareness about CC and effective actions to deal with CC, like education, training, lessons learned management and continuous improvement, are key to enhancing the resilience level of urban CIs. Furthermore, the CC perspective must be included in the planning of new infrastructures. For that reason, both the public and private sectors should consider more sustainable solutions in new infrastructure design. In this way, the main barriers identified by the experts in the workshops were a lack of political consensus and policy continuity, and the perception that the adoption of these practices will result in more expensive solutions.

In the interdependency analysis, the workshops showed that the CI experts are more aware of their own dependencies than the ones they generate. Thus, it is necessary to work harder to understand the long-term impacts derived from the interdependency relationships among CIs. Furthermore, the experts found it difficult to establish a time range for the criticality of the dependency, since the analysis has been sectorial. In this sense a more detailed analysis is needed, one that takes into account specific assets in order to set appropriate alternatives in case of failure and to improve infrastructure design.

$\mathrm{CC}$ does not affect every $\mathrm{CI}$ in the same way. Some are more vulnerable to certain sudden events, like extreme events, but others are more sensitive to long-term stressors, which are difficult to predict at the moment due to the uncertainty of CC projections. Further research is needed related to tools and methodologies that help to dismiss the effect of the uncertainty in order to develop more effective resilience strategies.

\section{Conclusions}

CC entails a huge challenge on a global scale as it is critical for urban environments. In this sense, cities are investing resources, money and time in developing mitigation, adaptation and resilience strategies. In the urban context, CIs play a major role in guaranteeing society's welfare. CC impacts must be taken into account both in terms of protection and adaptation of existing CIs and when planning the city of the future. This fact represents a big challenge as CI networks belong to or are operated, in most of the cases, by private companies. For that reason, the involvement of all the stakeholders during the co-creation process is of paramount importance to guarantee that the strategies include all the interests, needs and points of view.

Operationalising resilience is not an easy task. The guide presented here aims to help cities in the reflection process that identifies key issues for improving their resilience against CC. In this sense, cities will be better prepared to face CC-related crises. Moreover, it considers urban CIs to be key agents for building city resilience. In this sense, knowledge about urban CI networks and their interdependencies acquires relevance in the resilience strategy. 
The guide represents a starting point and a reference for developing and establishing a resilience strategy by providing cities with a framework to assess and improve their resilience level against CC by considering urban $\mathrm{CI}$.

In conclusion, CC represents a huge challenge, right now and for the future. In a changing environment where there is a high degree of uncertainty and unpredictability, resilience-based strategies are an opportunity to increase cities' capabilities to deal with current and future crises and to move towards a more sustainable future.

Author Contributions: All authors contributed to the paper. Introduction, state of art and discussion-C.L.-F., methodology, results and conclusion-C.L.-F., J.H., L.L., writing, review and editing-C.L.-F., J.H., L.L.

Funding: This research was funded by Sociedad Pública IHOBE S.A. under the contract Retos de innovación ambiental de la Administración Vasca, grant number 460906.

Conflicts of Interest: The authors declare no conflict of interest.

\section{References}

1. De Coninck, H.; Revi, A.; Babiker, M.; Bertoldi, P.; Buckeridge, M.; Cartwright, A.; Dong, W.; Ford, J.; Fuss, S.; Hourcade, J.C.; et al. Strengthening and implementing the global response. In Global Warming of $1.5^{\circ} \mathrm{C}$ : Summary for Policy Makers; IPCC: Geneva, Switzerland, 2018; p. 132.

2. Van Oldenbourg, G.J. Trends in Weather Extremes. February 2018. Available online: https://www. worldweatherattribution.org (accessed on 21 March 2019).

3. United Nations. World Urbanization Prospects: The 2018 Revision; United Nations Department of Economic and Social Affairs: New York, NY, USA, 2018; pp. 1-2.

4. Füssel, H.-M.; Marx, A.; Hildén, M.; Bastrup-Birk, A.; Louwagie, G.; Wugt-Larsen, F.; Suk, J. Climate Change, Impacts and vulnerability in Europe 2016; EEA: Copenhagen, Denmark, 2017; Volume 4. [CrossRef]

5. EU Commission. The EU Strategy on Adaptation to Climate Change.; EU Commission: Brussels, Belgium, 2013.

6. European Commission. A Clean Planet for All. A European Strategic Long-Term Vision for a Prosperous, Modern, Competitive and Climate Neutral Economy_Communication from the Commission to the European Parliament, the Council, the European and Social Committee and the Committee; EU Commission: Brussels, Belgium, 2018; p. 25.

7. Heidrich, O.; Reckien, D.; Olazabal, M.; Foley, A.; Salvia, M.; de Gregorio Hurtado, S.; Orru, H.; Flacke, J.; Geneletti, D.; Pietrapertosa, F. National climate policies across Europe and their impacts on cities strategies. J. Environ. Manag. 2016, 168, 36-45. [CrossRef] [PubMed]

8. Aguiar, F.C.; Bentz, J.; Silva, J.M.; Fonseca, A.L.; Swart, R.; Santos, F.D.; Penha-Lopes, G. Adaptation to climate change at local level in Europe: An overview. Environ. Sci. Policy 2018, 86, 38-63. [CrossRef]

9. Tyler, S.; Moench, M. A framework for urban climate resilience. Clim. Dev. 2012, 4, 311-326.

10. Department of Homeland Security. 2017. Available online: https:/www.dhs.gov/topic/critical-infrastructuresecurity (accessed on 15 February 2018).

11. EU Critical Infrastructures. 2017. Available online: https://ec.europa.eu/home-affairs/what-we-do/policies/ crisis-and-terrorism/critical-infrastructure_en (accessed on 5 March 2018).

12. Torabi, E.; Dedekorkut-Howes, A.; Howes, M. Urban Resilience to Climate-Related Disasters: Emerging Lessons from Resilience Policy and Practice in Coastal Tourism Cities. In Climate Change Adaptation in Pacific Countries; Spinger: Cham, Switzerland, 2017; pp. 241-254.

13. Laugé-Eizaguirre, A. Crisis Management Toolbox: The Relevant role of Critical Infrastructures and their Dependencies. PhD Thesis, University of Navarra, Pamplona, Spain, 2014.

14. Mikellidou, C.V.; Shakou, L.M.; Boustras, G.; Dimopoulos, C. Energy critical infrastructures at risk from climate change: A state of the art review. Saf. Sci. 2018, 110, 110-120. [CrossRef]

15. Wallace, W.A.; Sharkey, T.C.; Chow, J.H.; Mitchell, J.E.; Nguyen, H.; Nurre, S.G. Identification and Classification of Restoration Interdependencies in the Wake of Hurricane Sandy. J. Infrastruct. Syst. 2015, 22, 04015007.

16. Comes, T.; Van de Walle, B. Measuring disaster resilience: The impact of Hurricane Sandy on critical infrastructure systems. In Proceedings of the Eleventh International ISCRAM Conference, University Park, PA, USA, 18-21 May 2014; pp. 195-204. 
17. Revi, A.; Satterthwaite, D.E.; Aragón-Durand, F.; Corfee-Morlot, J.; Kiunsi, R.B.R.; Pelling, M.; Roberts, D.C.; Solecki, W. Urban areas. In Climate Change 2014: Impacts, Adaptation, and Vulnerability. Part A: Global and Sectoral Aspects. Contribution of Working Group II to the Fifth Assessment Report of the Intergovernmental Panel on Climate Change; Field, C.B., Barros, V.R., Dokken, D.J., Mach, K.J., Mastrandrea, M.D., Bilir, T.E., Chatterjee, M., Ebi, K.L., Estrada, Y.O., Genova, R.C., et al., Eds.; Cambridge University Press: Cambridge, UK; New York, NY, USA; pp. 535-612.

18. Hernantes, J.; Maraña, P.; Gimenez, R.; Sarriegi, J.M.; Labaka, L. Towards resilient cities: A maturity model for operationalizing resilience. Cities 2019, 84, 96-103. [CrossRef]

19. Folke, C.; Carpenter, S.; Elmqvist, T.; Gunderson, L.; Holling, C.S. Resilience and sustainable development: Building adaptive capacity in a world of transformations. AMBIO 2002, 31, 437-440. [CrossRef]

20. Hollnagel, E. Prologue: The scope of resilience engineering. In Resilience Engineering in Practice: A Guidebook; Ashgate Publishing, Ltd.: Farnham, UK, 2011; pp. 29-39.

21. Holling, C.S. Resilience and stability of ecological systems. Annu. Rev. Ecol. Syst. 1973, 4, 1-23. [CrossRef]

22. Madni, A.M.; Jackson, S. Towards a conceptual framework for resilience engineering. IEEE Syst. J. 2009, 3, 181-191. [CrossRef]

23. Thornbush, M.; Golubchikov, O.; Bouzarovski, S. Sustainable cities targeted by combined mitigationadaptation efforts for future-proofing. Sustain. Cities Soc. 2013, 9, 1-9. [CrossRef]

24. Leong, C. Resilience to climate change events: The paradox of water (In)-security. Sustain. Cities Soc. 2018, 27, 439-447. [CrossRef]

25. Curt, C.; Tacnet, J.M. Resilience of Critical Infrastructures: Review and Analysis of Current Approaches. Risk Anal. 2018, 38, 2441-2458. [PubMed]

26. Bruneau, M.; Chang, S.E.; Eguchi, R.T.; Lee, G.C.; O’Rourke, T.D.; Reinhorn, A.M.; Shinozuka, M.; Tierney, K.; Wallace, W.A.; Von Winterfeldt, D. A Framework to Quantitatively Assess and Enhance the Seismic Resilience of Communities. Earthq. Spectra 2003, 19, 733-752. [CrossRef]

27. Fu, G.; Wilkinson, S.; Dawson, R.J.; Fowler, H.J.; Kilsby, C.; Panteli, M.; Mancarella, P. Integrated Approach to Assess the Resilience of Future Electricity Infrastructure Networks to Climate Hazards. IEEE Syst. J. 2017, 12, 3169-3180. [CrossRef]

28. Francis, R.; Bekera, B. A metric and frameworks for resilience analysis of engineered and infrastructure systems. Reliab. Eng. Syst. Saf. 2014, 121, 90-103. [CrossRef]

29. Espinoza, S.; Panteli, M.; Mancarella, P.; Rudnick, H. Multi-phase assessment and adaptation of power systems resilience to natural hazards. Electr. Power Syst. Res. 2016, 136, 352-361. [CrossRef]

30. Panteli, M.; Mancarella, P. Modeling and evaluating the resilience of critical electrical power infrastructure to extreme weather events. IEEE Syst. J. 2017, 11, 1733-1742. [CrossRef]

31. Brown, C.; Seville, E.; Vargo, J. Measuring the organizational resilience of critical infrastructure providers: A New Zealand case study. Int. J. Crit. Infrastruct. Prot. 2017, 18, 37-49. [CrossRef]

32. Bram, S.; Degerman, H.; Melkunaite, L.; Urth, T.; Carreira, E. Organisational resilience concepts applied to critical infrastructure. IMPROVER EU Project Deliverable Number: D4.3, 2016. Available online: http:// improverproject.eu/2017/05/31/d-4-3-organisational-resilience-concepts-applied-to-critical-infrastructure/.

33. Labaka, L.; Hernantes, J.; Sarriegi, J.M. A holistic framework for building critical infrastructure resilience. Technol. Forecast. Soc. Chang. 2016, 103, 21-33. [CrossRef]

34. Shakou, L.M.; Wybo, J.L.; Reniers, G.; Boustras, G. Developing an innovative framework for enhancing the resilience of critical infrastructure to climate change. Saf. Sci. 2019, 118, 364-378.

35. Eusgeld, I.; Nan, C.; Dietz, S. System-of-systems approach for interdependent critical infrastructures. Reliab. Eng. Syst. Saf. 2011, 96, 679-686. [CrossRef]

36. Nan, C.; Sansavini, G. A quantitative method for assessing resilience of interdependent infrastructures. Reliab. Eng. Syst. Saf. 2017, 157, 35-53. [CrossRef]

37. Sansavini, G. Engineering resilience in critical infrastructures. In NATO Science for Peace and Security Series C: Environmental Security; Springer: Berlin, Germany, 2017.

38. Laugé, A.; Hernantes, J.; Sarriegi, J.M. Critical infrastructure dependencies: A holistic, dynamic and quantitative approach. Int. J. Crit. Infrastruct. Prot. 2015, 8, 16-23. [CrossRef]

39. Heino, O.; Takala, A.; Jukarainen, P.; Kalalahti, J.; Kekki, T.; Verho, P. Critical Infrastructures: The Operational Environment in Cases of Severe Disruption. Sustainability 2019, 11, 838. [CrossRef] 
40. Chang, S.E.; McDaniels, T.L.; Mikawoz, J.; Peterson, K. Infrastructure failure interdependencies in extreme events: Power outage consequences in the 1998 Ice Storm. Nat. Hazards 2007, 41, 337-358. [CrossRef]

41. Kanno, T.; Koike, S.; Suzuki, T.; Furuta, K. Human-centered modeling framework of multiple interdependency in urban systems for simulation of post-disaster recovery processes. Cogn. Technol. Work 2019, 21, 301-316. [CrossRef]

42. IPCC. Summary for policymakers. In Climate Change 2014: Impacts, Adaptation, and Vulnerability; Part A Glob. Sect. Asp. Contrib. Work. Gr. II to Fifth Assess. Rep. the I Intergovernmental Panel Clim. Chang.; Cambridge University Press: Cambridge, UK; New York, NY, USA; pp. 1-32.

43. Linkov, I.; Bridges, T.; Creutzig, F.; Decker, J.; Fox-Lent, C.; Kröger, W.; Lambert, J.H.; Levermann, A.; Montreuil, B.; Nathwani, J. Changing the resilience paradigm. Nat. Clim. Chang. 2014, 4, 407. [CrossRef]

44. Shen, S.; Feng, X.; Peng, Z.R. A framework to analyze vulnerability of critical infrastructure to climate change: The case of a coastal community in Florida. Nat. Hazards 2016, 84, 589-609. [CrossRef]

45. Lizarralde, G.; Chmutina, K.; Bosher, L.; Dainty, A. Sustainability and resilience in the built environment: The challenges of establishing a turquoise agenda in the UK. Sustain. Cities Soc. 2015, 15, 96-104. [CrossRef]

46. Marchese, D.; Reynolds, E.; Bates, M.E.; Morgan, H.; Clark, S.S.; Linkov, I. Resilience and sustainability: Similarities and differences in environmental management applications. Sci. Total Environ. 2018, 613, 1275-1283. [CrossRef]

47. Collier, M.J.; Nedović-Budić, Z.; Aerts, J.; Connop, S.; Foley, D.; Foley, K.; Newport, D.; McQuaid, S.; Slaev, A.; Verburg, P. Transitioning to resilience and sustainability in urban communities. Cities 2013, 32, S21-S28. [CrossRef]

48. Malalgoda, C.; Amaratunga, D.; Haigh, R. Challenges in Creating a Disaster Resilient Built Environment. Procedia Econ. Financ. 2014, 18, 736-744. [CrossRef]

49. Toubin, M.; Laganier, R.; Diab, Y.; Serre, D. Improving the Conditions for Urban Resilience through Collaborative Learning of Parisian Urban Services. J. Urban Plan. Dev. 2014, 141, 05014021. [CrossRef]

50. Godschalk, D.R. Urban Hazard Mitigation: Creating Resilient Cities. Nat. Hazards Rev. 2003, 4, $136-143$. [CrossRef]

51. Meerow, S.; Newell, J.P.; Stults, M. Defining urban resilience: A review. Landsc. Urban Plan. 2016, 147, 38-49. [CrossRef]

52. 100 Resilient Cities. Available online: https://www.100resilientcities.org/ (accessed on 15 May 2019).

53. SMR Project. Available online: http://smr-project.eu/home/ (accessed on 15 May 2019).

54. Smart Resilience. Available online: http://www.smartresilience.eu-vri.eu/ (accessed on 15 May 2019).

55. IMPROVER Project. Available online: http://improverproject.eu/ (accessed on 15 May 2019).

56. RESIN Project. Available online: http://www.resin-cities.eu/home/ (accessed on 15 May 2019).

57. Ouyang, M.; Wang, Z. Resilience assessment of interdependent infrastructure systems: With a focus on joint restoration modeling and analysis. Reliab. Eng. Syst. Saf. 2015, 141, 74-82. [CrossRef]

58. Zimmerman, R.; Restrepo, C.E. Analyzing cascading effects within infrastructure sectors for consequence reduction. In Proceedings of the IEEE Conference on Technologies for Homeland Security, HST 2009, Waltham, MA, USA, 11-12 May 2009; pp. 165-170.

59. Marana, P.; Labaka, L.; Sarriegi, J.M. A framework for public-private-people partnerships in the city resilience-building process. Saf. Sci. 2018, 110, 39-50. [CrossRef]

60. Voorberg, W.H.; Bekkers, V.J.J.M.; Tummers, L.G. A Systematic Review of Co-Creation and Co-Production: Embarking on the social innovation journey. Public Manag. Rev. 2015, 17, 1333-1357. [CrossRef]

61. Hennink, M.M. Focus Group Discussions; Oxford University Press: Oxford, UK, 2013.

62. Rinaldi, S.M. Modeling and simulating critical infrastructures and their interdependencies. In Proceedings of the 37th Annual Hawaii International Conference on System Sciences, Big Island, HI, USA, 5-8 January 2004; p. 8.

63. Pescaroli, G.; Nones, M.; Galbusera, L.; Alexander, D. Understanding and mitigating cascading crises in the global interconnected system. Int. J. Disaster Risk Reduct. 2018, 30, 159-163. [CrossRef]

64. ARUP. City Resilience Framework; ARUP Group Ltd.: London, UK, 2015; Available online: http://www. seachangecop.org/files/documents/URF_Bo. 
65. Sharifi, A.; Yamagata, Y. Resilient urban planning: Major principles and criteria. Energy Procedia 2014, 61, 1491-1495. [CrossRef]

66. Sharifi, A.; Yamagata, Y. Principles and criteria for assessing urban energy resilience: A literature review. Renew. Sustain. Energy Rev. 2016, 60, 1654-1677. [CrossRef]

(C) 2019 by the authors. Licensee MDPI, Basel, Switzerland. This article is an open access article distributed under the terms and conditions of the Creative Commons Attribution (CC BY) license (http://creativecommons.org/licenses/by/4.0/). 